\title{
Experiences of communication in the caring process by children aged 7-13 where there is a requirement for nitrous oxide for needle related procedures
}

\author{
Merja Vantaa Benjaminsson ${ }^{1}$, Stefan Nilsson*2 \\ ${ }^{1}$ Södra Älvsborg Hospital, Borås, Sweden \\ ${ }^{2}$ Institute of Health and Care Sciences, University of Gothenburg, Gothenburg, Sweden
}

Received: October 6, 2016

DOI: $10.5430 / \mathrm{cns} . v 5 \mathrm{n} 1 \mathrm{p} 13$
Accepted: December 11, 2016

Online Published: December 22, 2016

URL: http://dx.doi.org/10.5430/cns.v5n1p13

\begin{abstract}
The aim of the study was to describe the experiences of communication in the caring process for children aged 7-13 years when they receive nitrous oxide during needle-related examinations and treatments. The study was of a qualitative nature and has been viewed through the lens of qualitative content analysis. Seventeen children aged 7-13 years participated, and visual and textual information was used to prepare each child. The categories described the following important activities for communication: The child has the possibility to learn about the procedure; trust in communication is based on one's own experiences; the child is disturbed in the communication during the procedure; the healthcare professional is responsive to the situation of the child; and children's emotions affect the communication. The results show that the children appreciated procedure-specific information and they felt that they have knowledge of what is going to happen. Accordingly, the children feel that they can reduce their distress when they are in control.
\end{abstract}

Key Words: Child, Communication, Interviews, Nursing, Pain

\section{INTRODUCTION}

Fear is often the main issue associated with needle-related procedures $^{[1]}$ and access to information decreases the development of procedural fear in children. ${ }^{[2]}$ Children are afraid of needle-related procedures because they see them as nasty and menacing. However, children aged $7-13$ years can comprehend that it is sometimes necessary to endure such procedures if healthcare professionals and parents explain and prepare them in a way that is appropriate to their level of understanding. ${ }^{[1]}$ Piaget says that $7-13$ years old children are at the concrete operational stage. In this stage, the children have more advanced language skills and a desire to be able to cope with situations. There is an increased awareness of the body and its parts and functions, which results in a fear of the loss of body parts, disability, and loss of control. ${ }^{[3]}$ When a failure in communicating occurs, feelings of distress or pain cause unnecessary suffering for children. ${ }^{[4]}$

The concept of needle-related procedures is often used in conjunction with, for example, injections, venepunctures, sutures, and lumbar punctures. ${ }^{[5]}$ However, pin-drawing is often associated with similar discomfort and pain, as are other needle-related procedures. ${ }^{[6]}$ These needle-related procedures require that children are given sufficient pain management, such as sedation with 50\% nitrous oxide and 50\%

\footnotetext{
* Correspondence: Stefan Nilsson; Email: stefan.nilsson.4@gu.se; Address: Sahlgrenska Academy at University of Gothenburg, Institute of Health and Care Sciences, Box 457, 40530 Gothenburg, Sweden.
} 
oxygen in combination with a eutectic mixture of local anaesthetic (EMLA), i.e. lidocaine $25 \mathrm{mg} / \mathrm{g}$ and prilocaine $25 \mathrm{mg} / \mathrm{g}$ cream. ${ }^{[7]}$ Another evidence-based pain management strategy used with needle-related procedures is distraction, ${ }^{[5]}$ which often is combined with $50 \%$ nitrous oxide and $50 \%$ oxygen.

According to the United Nations Convention on the Rights of the Child, ${ }^{[8]}$ children have the right to receive information in a way that is appropriate to their age and development, and efforts should be made to reduce physical and mental stress. The United Nations Convention on the Rights of Persons with Disabilities ${ }^{[9]}$ further states that parties must take appropriate measures to ensure that persons with disabilities have access to information on the same basis as others (UN Convention 4.3.3 Article 9). A universal design should be used in all communication interventions. These interventions should be routinely implemented with all families of children in a healthcare setting, rather than with a specific target group. ${ }^{[9]}$

In this study, we used the caring process, the four basic phases of which are identification, planning, implementation, and evaluation. ${ }^{[10]}$ The caring process can be described as follows: In the identification phase, children are observed to have a disease or trauma, and they answer questions about this. In the planning phase, the healthcare professionals inform the children about further arrangements. During the implementation phase, the healthcare professionals carry out the care activities that they have earlier informed the children about. The children are asked afterwards, in the evaluation phase, about how they felt during the procedure.

\section{Aim}

The aim of the study was to describe the experiences of communication in the caring process for children aged 7-13 years when they receive nitrous oxide during needle-related examinations and treatments.

\section{METHOD}

\subsection{Participants}

Seventeen children aged 7-13 years were chosen, based on strategic selection, at a paediatric department in Västra Götaland. All the children were given a universal design, that is, visual and textual information (see Figure 1), which was sent to their home prior to the needle-related procedure. The children also underwent a needle-related procedure with $50 \%$ nitrous oxide and $50 \%$ oxygen sedation. The decision of $50 \%$ nitrous oxide and $50 \%$ oxygen sedation was taken by a physician, and the decision was based on the predicted level of distress for the child.

The inclusion criteria were as follows: (1) The patients spoke
Swedish; (2) The patients could be interviewed on the day of the needle-related procedure.

All of the children who were asked about participation chose to participate, resulting in a total of nine boys and eight girls (see Table 1).

\subsection{Data collection}

A researcher (MVB) collected data about the child's experiences of communication in the caring process. An interview guide was developed and pilot was tested with one child. The questions were well understood; thus, it was decided to include this patient's data in the study.

The semi-structured interview was conducted in a private room at the hospital 0.5-2 hours after the needle-related procedure was completed. The children were asked if they wanted the parent present during the interview; the five oldest children chose not to have their parent present. The interviewer was not the person who had given the information or the medicine, nor was the interviewer involved in the procedure.

To help facilitate the interview, the children received stimulus material in the form of the image support sent to their home and the breathing mask in which they received nitrous oxide and oxygen. The interviews were digitally recorded and transcribed verbatim with pauses, laughter, and other sounds to capture the atmosphere during the interview. The interviews were conducted from November 2013 to July 2014 and lasted for a median of 15 minutes (range 8-23 minutes).

\subsection{Data analysis}

The interviews were processed by an inductive analysis process, as described by Elo and Kyngäs. ${ }^{[11]}$ Meaning units were selected from the printed interview text, and these formed the condensed meaning units that were grouped into codes. The researchers discussed discrepancies until an agreement was reached. All of the codes were then grouped into subcategories that reflected the communication in conjunction with needle-related procedures. These subcategories were abstracted in the next step of the analysis into categories. ${ }^{[1]}$

\subsection{Ethical considerations}

Written information was provided to the parents and was accompanied by verbal information given to the children. If the children agreed to participate, the parents were asked for written consent. The voluntary nature of the study, as well as the right to withdraw from the study at any time without any explanation and consequences, was highlighted. The study was carried out in accordance with the ethical guidelines laid down in the Helsinki Declaration. ${ }^{[12]}$ 


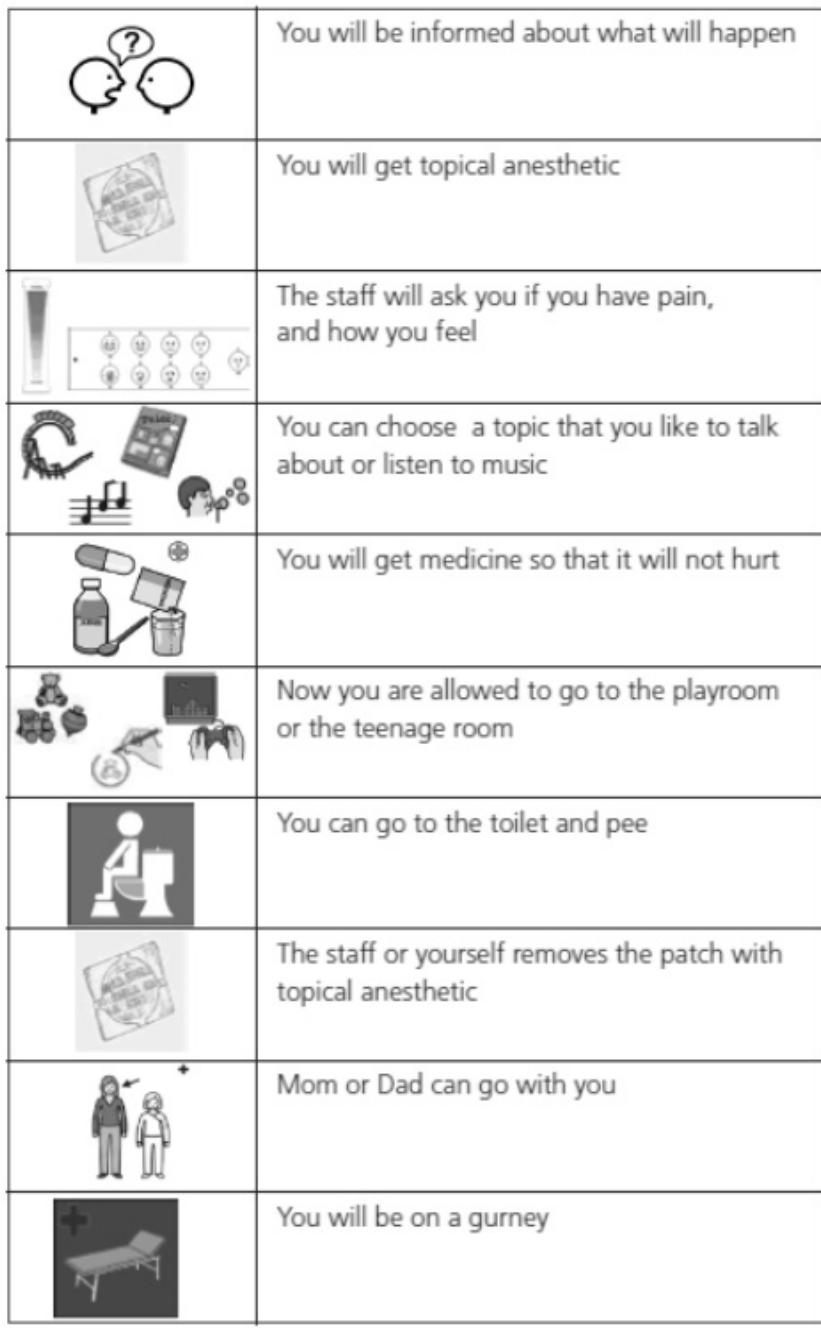

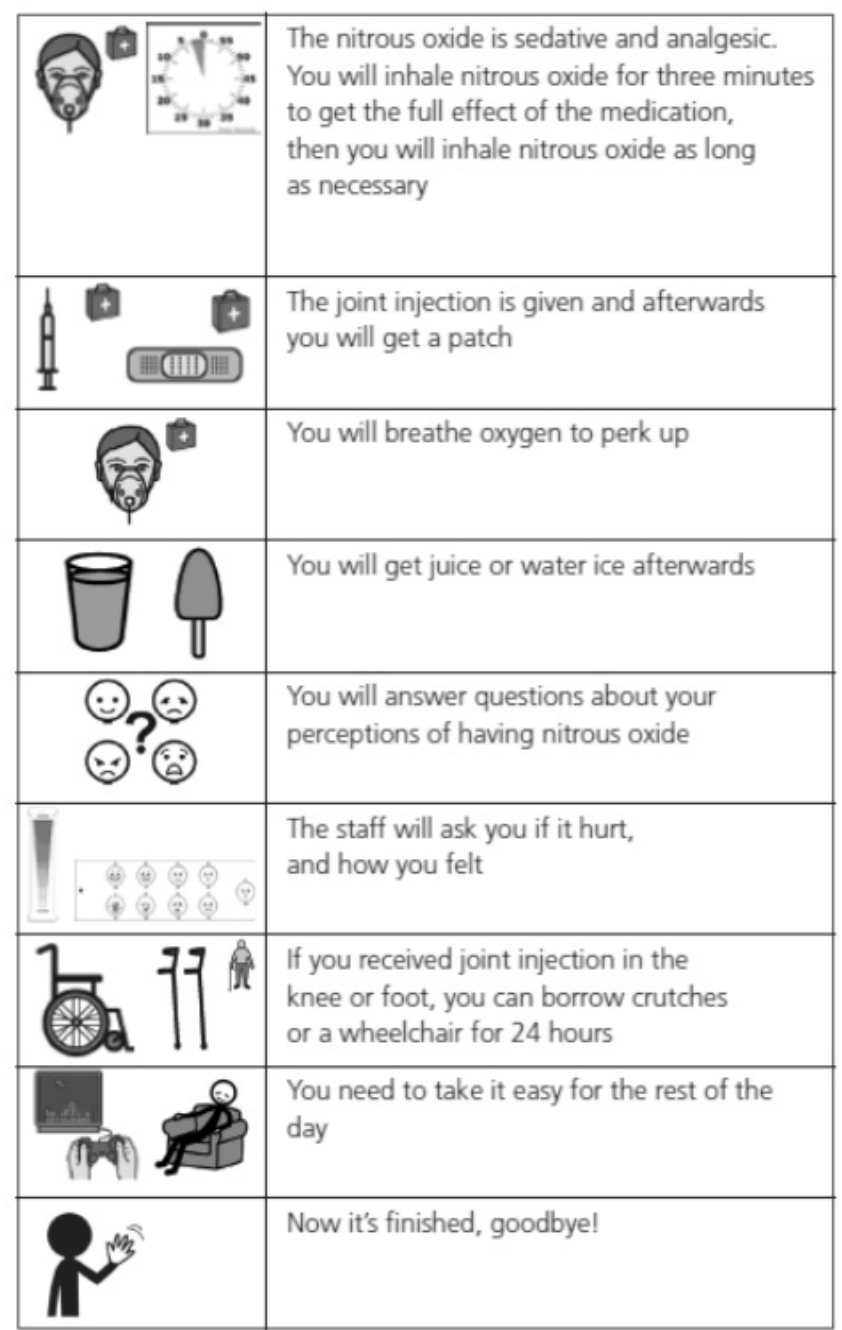

Figure 1. Visual and textual information

Table 1. Demographic data

\begin{tabular}{llllll}
\hline & Pin removal & Lumbar puncture & Joint injection & Venepuncture & Sutures \\
\hline Boys (n) & 5 & 1 & 1 & 2 & 0 \\
Age (years) & $7,8,8,9,12$ & 10 & 12 & $12,13^{*}$ & - \\
Girls (n) & 3 & 2 & 2 & 0 & 1 \\
Age (years) & $8,12,13$ & $13^{*}, 13$ & 10,13 & - & 7 \\
Negative hospital experience (n) & 0 & 0 & 0 & 2 & 0 \\
Earlier experience of nitrous oxide sedation (n) & 1 & 1 & 3 & 1 & 0 \\
Earlier experience of the same needle-related & 1 & 1 & 3 & 0 & 0 \\
procedure (n) & 0 & 1 & 0 & & 0 \\
Neuropsychiatric diagnosis (*) & & &
\end{tabular}

\section{RESUlts}

The results are based on five main categories and sixteen subcategories (see Table 2), and these categories contain children's opinions about what matters when it comes to communication in conjunction with needle-related procedures. They are aware of the adults' behaviours and of whether the adults are telling the truth about the procedure. If the adults are skilful in their communication, the children believe that they can cope better with the procedure.

\subsection{The child has the possibility to learn about the pro- cedure}

The children reported that they learned about the needlerelated procedure by communicating with their parents and the healthcare professionals. 
Table 2. Categories and subcategories

\begin{tabular}{|c|c|}
\hline Categories & Subcategories \\
\hline $\begin{array}{l}\text { The child has the possibility to learn } \\
\text { about the procedure }\end{array}$ & $\begin{array}{l}\text { - The mother explains to the child what will happen } \\
\text { - The healthcare professionals provide information about the needle-related procedure } \\
\text { - The children tell their own family about the needle-related procedure } \\
\text { - The information at the hospital is understandable and sufficient }\end{array}$ \\
\hline $\begin{array}{l}\text { Trust in communication is based on } \\
\text { one's own experiences }\end{array}$ & $\begin{array}{l}\text { - Children feel trust based on past experiences } \\
\text { - The communication is consistent with the expectations }\end{array}$ \\
\hline $\begin{array}{l}\text { The child is disturbed in the } \\
\text { communication during the procedure }\end{array}$ & $\begin{array}{l}\text { - There is insufficient communication mediation } \\
\text { - The children's communication is impaired when they receive sedating medication } \\
\text { - Interruptions in communication disturb the children }\end{array}$ \\
\hline $\begin{array}{l}\text { The healthcare professional is } \\
\text { responsive to the situation of the child }\end{array}$ & $\begin{array}{l}\text { - The children are involved in the choice of the method of distraction } \\
\text { - The healthcare professional is responsive and adjusts the intensity of communication } \\
\text { during the procedure } \\
\text { - How the children perceive the pain is important to them }\end{array}$ \\
\hline $\begin{array}{l}\text { Children's emotions affect the } \\
\text { communication }\end{array}$ & $\begin{array}{l}\text { - The information has an effect on the children's feelings } \\
\text { - Distracting communication is soothing } \\
\text { - The fear of web-based information increases stress } \\
\text { - Encouragement makes the children stronger }\end{array}$ \\
\hline
\end{tabular}

\subsubsection{The mother explains to the child what will happen}

The children expressed that when their mothers explained the procedure to them, they spoke of their own experiences of hospital visits and about being given nitrous oxide during delivery. Hence the mother's experience of nitrous oxide affected the child's pre-understanding of the needle-related procedure if he or she had not received this medical gas before.

"Um, my mother told me what would happen and such ... So I knew."

\subsubsection{The healthcare professionals provide information about the needle-related procedure}

The children often registered that they had received some verbal information from the healthcare professionals, that is, nurses and physicians. The information on how the needlerelated procedure would take place was given before the hospital visit. On the whole, they understood the information but could not fully comprehend what was going to happen and what it would be like.

"Then they said to me that in three weeks I would get nitrous oxide and have the pins removed."

It was harder for the children to say who had given them the information, and often they referred to the healthcare professional as a doctor or "somebody". The children who were hospitalized for the investigation of a disease or who had a chronic illness could remember the person who had provided them with the information and hence name them.

"It was, like, someone who told us that we would get nitrous oxide and such."

\subsubsection{The children tell their own family about the needle- related procedure}

The children explained that, after they received visual and textual information, they talked to their family, but not to anyone else, about what they would undergo at the hospital. The mother already knew what would happen, so the children mentioned telling their father and siblings about it.

"Yes, I've talked to my little sister and my dad, but no one else really."

\subsubsection{The information at the hospital is understandable and sufficient}

The children reported that the visual and textual information enabled them and their parents to review and discuss what would happen, and the needle-related procedure was de-dramatized. The children felt that they had an understanding of what was going to happen and as such were perceived as being less anxious.

"Like, it's good to have both pictures and text because it's like you understand it better. . . That's how they explained it and such. Yes, I thought it was good that we received [some] because then you felt a little bit more [thinking] um, prepared."

The interviewer noticed that the pictures and the text information were also understandable for school children with neuropsychiatric problems and made it easier for them to understand what would happen at the hospital.

ISSN 2324-7940 E-ISSN 2324-7959 
"She read a text, or I got to see some pictures, which was okay, they were good, or I got to see what I would do . . . I understood that I would do this [showing with his hand the mask towards the mouth]."

\subsection{Trust in communication is based on one's own expe- riences}

The children drew confidence from their parents' and the healthcare professionals' experiences of the needle-related procedure. The children's previous experiences of similar needle-related procedures also helped them to trust the information given to them.

\subsubsection{Children feel trust based on past experiences}

The children reported that when they had been through similar needle-related procedures, they were confident about what would happen at the hospital and felt able to trust the information that was provided. The researcher noticed that children who had not experienced the needle-related procedure before but who had received verbal, visual, and textual information were often calm but nervous. The children became more anxious just before the procedure, because they did not fully trust the information, as they had not been through it before.

"A little nervous [giggling], a bit like that, a little bit of stomach ache and because, uh yes, I hadn't done this before."

\subsubsection{The communication is consistent with the expecta- tions}

The children told the researcher that it was important for them that the information was not deceptive and that the information given by the parents and caregivers was consistent with what subsequently happened. In this way, the children felt that they were in control of the situation and that they could follow what was happening.

"Well, it was like I imagined it would be."

\subsection{The child is disturbed in the communication during the procedure}

The researcher found that children could not always recall that they had been given information by the healthcare professionals before or in connection with the needle-related procedure. The children were also disturbed during the needle-related procedure if the staff were interrupted in their communication with them.

\subsubsection{There is insufficient communication mediation}

Sometimes, the children did not remember what had been said, but they knew that they had received some form of verbal information. The children also felt that the parent was reluctant to go through the pictures and the text information with them.

Published by Sciedu Press
"Yes, she did. But I just can't remember it."

\subsubsection{The children's communication is impaired when they receive sedating medication}

The children said that their communication was worsened when sedation such as nitrous oxide was administered in conjunction with the needle-related procedure. The children felt dizzy and they did not remember the communication, and sometimes they could only hear those who were near.

"Ummm [thinking], I don't remember. [Thinking] After the nitrous oxide I actually don't remember much, but uh, I don't remember the small talk but I do remember what happened and so, but I cannot remember everything."

\subsubsection{Interruptions in communication disturb the chil- dren}

The children reported that they were disturbed if the healthcare professionals' full attention was not on communicating with them. This happened when the healthcare professionals were interrupted because the phone rang or because someone else came into the room.

"She first held the mask and then someone called and she had to pick up the phone. Then she said she didn't want to talk and then she held the mask again."

3.4 The healthcare professional is responsive to the situation of the child

This category describes how healthcare professionals are attentive to the wishes of the children and simultaneously sense their needs during the needle-related procedure. At home, the children had understood that the healthcare professionals would ask if they were in pain or if they felt anxious as well as about the kind of distraction method that they had decided to be exposed to during the procedure.

\subsubsection{The children are involved in the choice of the method of distraction}

The children said that, when they were at the hospital, they were asked by the healthcare professionals what distraction they wanted, or they were given suggestions on methods of distractions, if they were undecided. The healthcare professionals were responsive to the wishes of the children as far as possible.

"Yes, we prepared that at home, or they said that I could listen to music."

\subsubsection{The healthcare professional is responsive and ad- justs the intensity of communication during the pro- cedure}

The children told the researcher that they had chosen the method of distraction before the needle-related procedure, 
but this was not always enough. Sometimes, the children became scared and anxious and felt that it had started to hurt. Then, the healthcare professional was responsive and attentive to this fear. They gave extra support to the children by adapting the intensity of communication or changing the method of distraction.

"I don't really know how I could hear, but first I was, I panicked a little when I got it and it started to ache. Then I was a little bit scared. And that is why she started telling me about the divers and ocean and such."

\subsubsection{How the children perceive the pain is important to them}

The children reported that, at home, they had had their attention drawn by the images and text information to the fact that they could be in pain. It was important for the children that the healthcare professionals asked them how they were doing and whether they were in pain. It turned out that if the healthcare professional forgot to ask the children to selfreport their pain experience, the children themselves asked about it.

"The staff ask if it is painful and how it feels now, yes. It was good."

\subsection{Children's emotions affect the communication}

The children said that the information could be both disturbing and comforting at the same time and that it also provided an opportunity to talk through what would happen. The communication was reassuring during the procedure itself, and the children's anxiety also decreased if the adults reassured them and if they spoke encouragingly to them about how to behave during the needle-related procedure.

\subsubsection{The information has an effect on the children's feel- ings}

The children reported that, when they first saw the pictures and the text information, certain pictures caused concerns. However, as they could look at and discuss the pictures at home, their fears and concerns decreased, and they felt prepared, in the sense that they knew what awaited them.

The children could be concerned about the level of pain, but when they read the information, they understood that they would receive pain relief. The fact that both the healthcare professionals and the relatives had calmed them down and told them about how to behave made the children stronger. The information given also helped the children to calm down.

"First I didn't want to see the picture with the needle but then you did not see the needle so much and then it looked like when you take a sample of blood in the arm, but a very big arm . . . I felt that, I can do that."

\subsubsection{Distracting communication is soothing}

The children said that they became calmer and had other things on their minds when the healthcare professionals provided information about the needle-related procedure or when relatives diverted their attention by talking. Many of the children said that it felt good when they were talking about something they thought was fun.

"Hmm, they talked, Mum and, um, the nurse talked, talked about Liseberg (an amusement park) . . . I thought it was good actually because then you got something to concentrate on ...”

\subsubsection{The fear of web-based information increases stress}

The children had not searched for web-based information. They did not feel this was necessary because they already had enough information. Nevertheless, there was a fear of what they could find on the Internet. That is, the children were afraid that online information would increase their concerns about the needle-related procedure.

"I thought that if I would go on the web it might say something scary."

\subsubsection{Encouragement makes the children stronger}

The children thought that it was reassuring that both the parents and the healthcare professionals said that the needlerelated procedure was nothing to worry about and that it would all go well. The children reacted positively to the fact that the healthcare professionals told them how to behave during the procedure to avoid becoming stressed.

"Mum said that it was nothing to worry about, that it would go well, and Dad said the same thing."

\section{Discussion}

The findings demonstrated that the children were satisfied with the information given and that they often appreciated knowing beforehand what would happen during the procedure. However, earlier experiences of the procedure influenced their feelings, and these feelings were the main cause of the children's fear. This is in accordance with earlier research, which found that children's experiences of similar procedures have proved significant in their experience of stress. ${ }^{[13]}$ Accordingly, pain memories can be interpreted as an important factor in their undergoing the procedure without resistance. Another study showed that children's expectations of a needle-related procedure are based on their previous experiences, knowledge, and self-image. ${ }^{[1]}$ A childcentred qualitative improvement with increased pain knowledge among the healthcare professionals can be beneficial in child care. ${ }^{[13]}$

The children perceived the encouraging comments from the 
mother and healthcare professionals as positive and reassuring. This communication led the children to feel calmer, and they were able to undergo the needle-related procedure more easily. According to Blount et al., ${ }^{[14]}$ words such as "Don't worry" can be stressful for children. However, this could not be verified in this study as the children found such words reassuring. One possible explanation for the results of this study could be the fact that the parents were well informed before the procedure and thus could calm and support their child.

Research has shown that parents may either worry or calm their child, depending on whether they show concern and fear in their facial expressions or body language when they try to provide supportive comments. Several studies have shown the negative effects of mothers transferring their negative feelings and experiences to their children. ${ }^{[15]}$ The results showed that the mother was the key to communication. The children mentioned that, at home, it was only the mother who transferred knowledge to them before the needle-related procedure. The children gained confidence from their mothers' experience, and it was important for them to know whether their mother had been through similar procedures. Most mothers have experienced nitrous oxide sedation in connection with childbirth, ${ }^{[16]}$ and the mothers in this study shared their own experiences of nitrous oxide sedation in order to de-dramatize the procedure. This study therefore showed that the mothers' experiences were perceived as a tonic for the children.

The children were given the opportunity to reflect on their thoughts with their parents before the procedure. De Freitas et al. ${ }^{[4]}$ argued that the ability to communicate reduces anxiety and pain-related experiences by children that can otherwise lead to unnecessary suffering.

The children's knowledge of what would happen in the hospital reduced their anxiety, giving them control of the situation. The children could be more involved in the needle-related procedure because they knew what would happen. Coyne ${ }^{[17]}$ showed that, when children receive information and ask for advice regarding their care, they feel happy and calm. In these cases, the children are treated as persons with rights. According to Ayers et al., ${ }^{[18]}$ the most common strategy of coping is to gain control over the situation, which is probably the foundation of the children's coping strategies. The children could also demand that healthcare professionals follow the visual and textual information, and they made sure that the healthcare professionals let them report their pain. If the healthcare professionals missed this, the child reminded them. Lack of documented pain assessment has been identified as an obstacle to optimal pain management in child

Published by Sciedu Press healthcare. ${ }^{[19]}$

The healthcare professionals were responsive to the children and tailored the communication to their needs. This was important because the children's pre-distraction method was not always enough when it was time for the procedure. The healthcare professionals noticed this and could then change the distraction method to suit the situation and then calm the children as much as possible. Forsner, Janssson and Söderberg ${ }^{[20]}$ suggested that, when children are frightened and anxious, they need to deal with responsive, calm, and gentle healthcare professionals.

Sedating medication leads to impaired communication. Therefore, the communication skills of the children were impaired during the needle-related procedure, not only because of the medication but also because of the mask. The results showed that the children felt "dizzy" and had difficulty answering questions. They did try to ask questions, however. Sound was perceived differently, and they could usually only hear those who were closest. The children could have had a different perception of reality and did not always remember what the healthcare professionals talked about during the procedure. Nitrous oxide sedation has been shown, in other studies, to produce different effects on the experience of a procedure, but these experiences are fleeting. ${ }^{[21]}$

There was a fear among the children that the information they would find on the Internet would be incorrect and scary. It is a known issue that individuals who look for information on the Internet feel that the information is not reliable. ${ }^{[22]}$ This stresses healthcare professionals to help children to find procedure-specific and truthful information which is consistent with how the procedure will be conducted.

Procedural comfort care must always start with a childfriendly and non-threatening environment. ${ }^{[23]}$ Healthcare professionals have an obligation to enable parents to support their child during an unpleasant needle-related procedure as well as to reduce the anxiety and pain experienced by the child. ${ }^{[24]}$ Training of healthcare professionals in combination with a checklist increases the likelihood that they inform the children, hence improving their ability to give personalized information. ${ }^{[25]}$

Clinical implications of this study are that healthcare professionals need to give children information about the needlerelated procedure, and this information needs to be adapted to the child's level of cognition. In addition, visual and textual information may facilitate the preparation of each child.

\section{Methodological considerations}

There are some limitations in this study that justify the need for further research in the subject area. For example, the 
study population was small, and there was no possibility of collecting additional data, such as observations to confirm compliance with the treatment. In addition, the subjects are weighted toward somewhat younger boys and older girls. Another limitation of the study is the risk of the parents influencing the children. However, Teachman and Gibson ${ }^{[26]}$ argued that parental involvement is important to establish a safe and comfortable situation for data collection. The parents were mostly silent, but sometimes they could help the children to understand the questions.

Trustworthiness was achieved in this study. The identified codes were independently verified by the second author, which strengthened the credibility and dependability in this study. The characteristics of the participants are described in this study in order to achieve transferability to other similar contexts. ${ }^{[27]}$

\section{Conclusions}

Based on the findings, children appreciate a feeling of control, and they think that healthcare professionals need to have knowledge of procedure-specific information that can be interpreted by the child. This can allow healthcare professionals to create individualized verbal information as well as image and textual information and support.

\section{ACKNOWLEDGEMENTS}

We would like to thank the participants of the study, who generously shared their time and experiences.

\section{CONFlicts OF INTEREST Disclosure}

None.

\section{REFERENCES}

[1] Forsner M, Nilsson S, Finnström B, et al. Expectation prior to HPVvaccination 11-12 year old girl's written narratives. Journal of Child Health Care. 2015; 20(3): 365-373. https ://doi.org/10.1177/ 1367493515598646

[2] Cohen LL. Behavioral approaches to anxiety and pain management for pediatric venous access. Pediatrics. 2008; 122 Suppl 3: S134-139. https ://doi.org/10.1542/peds.2008-1055f

[3] Piaget J, Inhelder B. The Psychology of the Child. Basic Books, New York; 1969.

[4] De Freitas GR, de Castro C, Castro SM, et al. Degree of Knowledge of Health Care Professionals About Pain Management and Use of Opioids in Pediatrics. Pain Medicine. 2014; 15(5): 807-819. https://doi.org/10.1111/pme.12332

[5] Birnie KA, Noel M, Parker JA, et al. Systematic Review and MetaAnalysis of Distraction and Hypnosis for Needle-Related Pain and Distress in Children and Adolescents. Journal of Pediatric Psychology. 2014; 39(8): 783-808. https ://doi.org/10.1093/jpepsy /jsu029

[6] Lim K, Tan SS, Abdullah SN, et al. Percutaneous pin removal in the outpatient clinic - do children require analgesia?: a randomized controlled trial. Journal of Bone and Joint Surgery. 2014; 96(7): 597-602. https://doi.org/10.2106/JBJS.M.00806

[7] Carbajal B, Lenclen E, Cimerman T, et al. EMLA cream and nitrous oxide to alleviate pain induced by palivizumab (Synagis) intramuscular injections in infants and young children. Pediatrics. 2008; 121(6): 1591-1598. https : //doi.org/10.1542/peds. 2007-3104

[8] United Nations. Convention on the rights of the child document. A/RES/44/25. 1989.

[9] United Nations. Final report of the Ad Hoc Committee on a Comprehensive and Integral International Convention on the Protection and Promotion of the Rights and Dignity of Persons with Disabilities. 2006.

[10] Kärkkäinen O, Eriksson K. Structuring the documentation of nursing care on the basis of a theoretical process model. Scandinavian Journal of Caring Science. 2004; 18(2): 229-236. PMid: 15147487. https://doi.org/10.1111/j.1471-6712.2004.00274.x
[11] Elo S, Kyngäs H. The qualitative content analysis process. Journal of Advanced Nursing. 2008; 62: 107-115. https://doi.org/10 $.1111 / \mathrm{j} .1365-2648.2007 .04569 . \mathrm{x}$

[12] World Medical Association. Declaration of Helsinki Ethical Principles for Medical Research Involving Human Subjects. https : //doi.org/10.1001/jama.2013.281053

[13] Nilsson S, Forsner M, Finnström B, et al. Relaxation and guided imagery do not reduce stress, pain and unpleasantness for 11 to 12 year-old girls during vaccinations. Acta Paediatrica. 2015; 104(7): 724-729. https://doi.org/10.1111/apa.13000

[14] Blount RL, Corbin SM, Sturges JW, et al. The relationship between adults' behavior and child coping and distress during BMA/LP procedures: a sequential analysis. Behavior Therapy. 1989; 20(4): 585-601. https : //doi .org/10.1016/S0005-7894(89)80136-4

[15] Dunne G, Askew C. Vicarious learning and unlearning of fear in childhood via mother and stranger models. Emotion. 2013; 13(5): 974-980. https://doi.org/10.1037/a0032994

[16] Waldenström U, Irestedt L. Obstetric pain relief and its association with remembrance of labor pain at two months and one year after birth. Journal of Psychosomic Obstetrics and Gynaecolaegy. 2006; 27(3): 147-156. https://doi.org/10.1080/01674820500433 432

[17] Coyne I. Consultation with children in hospital: children, parents 'and nurses'perspectives. Journal of Clinical Nursing. 2006; 15(1): 61-67. PMid: 16390525. https ://doi.org/10.1111/j.1365-2 702.2005.01247.x

[18] Ayers S, Muller I, Mahoney L, et al. Undergoing needle-related distress in children with cystic fibrosis. British Journal of Health Psychology. 2011; 16(Pt 2): 329-343. https : //doi .org/10.134 8/135910710X506895

[19] Kozlowski LJ, Kost-Byerly S, Colantuoni E, et al. Pain prevalence, intensity, assessment and management in a hospitalized pediatric population. Pain Management Nursing. 2014; 15(1): 22-35. https ://doi.org/10.1016/j.pmn.2012.04.003

[20] Forsner M, Janssson L, Söderberg A. Afraid of Medical Care: SchoolAged Children's Narratives About Medical Fear. Journal of Pediatric Nursing. 2009; 24(6): 519-528. https://doi.org/10.1016/j . pedn. 2009.08 .003 
[21] Hee HI, Goy RW, Ng AS. Effective reduction of anxiety and pain duringvenous cannulation in children: a comparison of analgesic efficacy conferred by nitrous oxide, EMLA and combination. Paediatric Anaesthesia. 2003; 13(3): 210-216. PMid: 12641682. https://doi.org/10.1046/j.1460-9592.2003.01051.x

[22] Beck F, Richard JB, Nguyen-Thanh V, et al. Use of the internet as a health information resource among French young adults: results from a nationally representative survey. Journal of Medical Internet Research. 2014; 16(5): 16:e128. https://doi.org/10.2196/jm ir. 2934

[23] Leroy PL, Costa LR, Emmanouil D, et al. Beyond the drugs: nonpharmacologic strategies to optimize procedural care in children. Current Opinion in Anaesthesiology. 2016; Suppl 1: S1-13. https: //doi.org/10.1097/AC0.0000000000000312

[24] Lawes C, Sawyer L, Amos S, et al. Impact of an education pro- gramme for staff working with children undergoing painful procedures. Paediatric Nursing. 2008; 20(2): 33-37. PMid: 18350861. https://doi.org/10.7748/paed2008.03.20.2.33.c6528

[25] Rosenberg RE, Klejmont L, Gallen M, et al. Making Comfort Count: Using Quality Improvement to Promote Pediatric Procedural Pain Management. Hospital Pediatrics. 2016; 6(6): 359-68. https://doi.org/10.1542/hpeds . 2015-0240

[26] Teachman G, Gibson B. Children and Youth With disabilities: Innovative Methods for Single qualitative Interviews. Qualitative Health Research. 2013; 23(2): 264-274. https://doi .org/10.1177/10 49732312468063

[27] Graneheim HU, Lundman B. Qualitative content analysis in nursing research: concepts, procedures and measures to achieve trustworthiness. Nurse Education Today. 2004; 24(2): 105-112. PMid: 14769454. https://doi.org/10.1016/j.nedt.2003.10.001 